\title{
A COMPARAÇÃO ENTRE DOCUMENTOS OFICIAIS EM LÍNGUA MATERNA E ESTRANGEIRA: A NECESSIDADE DE UM OLHAR MAIS AMPLO PARA OS CONTEXTOS DE PRODUÇÃO E CIRCULAÇÃO DOS TEXTOS
}

\section{COMPARISON BETWEEN OFFICIAL DOCUMENTS IN NATIVE AND FOREIGN LANGUAGE: THE NEED FOR A BROAD LOOK FOR PRODUCTION CONTEXT AND MOVEMENT OF TEXTS}

\author{
Ana Cecília Gama Torres \\ Doutora em Letras pela Universidade Federal de Santa Catarina \\ Professora do Instituto Federal de Educação Ciência e Tecnologia de Santa Catarina \\ E-mail: anagamatorres@gmail.com
}

\section{Eliza Cristina de Oliveira}

Graduanda em Ciências da Natureza pelo Instituto Federal de Educação Ciência e Tecnologia de Santa Catarina Bolsista de extensão no Instituto Federal de Educação Ciência e Tecnologia de Santa Catarina E-mail: eliza_cristina@live.com

\section{RESUMO}

A proposta inicial deste trabalho era comparar as diretrizes oficias (brasileira e americana) na área de física para o ensino médio, especificamente, o PCN+ (2002) e o NGSS (New Generation Science Standards, 2013). Observamos que os contextos de produção e de circulação do texto brasileiro e do americano são distintos, o que inibiu a comparação entre a proposta nacional e a estrangeira. Apesar dessa dificuldade, observamos que é importante visualizar os contextos de produção/ circulação dos documentos oficiais a partir das suas várias dimensões: socioeconômica, histórica e no âmbito da própria escola, no cotidiano de suas salas de aula. Concluímos que as possibilidades de significação dos documentos oficiais estão entrelaçadas ao dinamismo desses contextos. Assim, ainda que a diretriz brasileira se encontre consubstanciada pela LDB 9394/96 e pela própria Constituição Federal/88 e também em conformidade com as pesquisas na área, isso não é suficiente para assegurar o seu cumprimento ou restringir as suas possibilidades de significação.

Palavras-chave: Diretrizes oficias. Contextualização. Dinamismo. Currículo Nacional Comum.

\section{ABSTRACT}

The initial purpose of this study was to compare the official guidelines (Brazilian and American) in Physics for high school, specifically, the PNC+ (2002) and the NGSS (New Generation Science Standards, 2013). We note that the Brazilian production contexts and the movement of texts are 
different from the American ones, which inhibited the comparison between the national and the foreign proposed. Despite this difficulty, we note that it is important to view the contexts of production / circulation of official documents from its various dimensions: socio-economic, historical, and within the school itself, in their everyday classrooms. We conclude that the possibilities of meaning of official documents are intertwined to the dynamism of these contexts. Thus, although the Brazilian guideline is substantiated by the LDB 9394/96 and by the Federal Constitution / 88 and also in accordance with the research in the area, this is not enough to ensure compliance or restrict its meaning possibilities.

Keywords: Official guidelines. Contextualization. Dynamism. Common National Curriculum.

\section{INTRODUÇÃO}

A proposta inicial deste trabalho era comparar as diretrizes oficias (brasileira e americana) na área de educação científica para o ensino médio, especificamente, no campo do ensino de física. Ponderamos que qualquer comparação entre documentos de países diferentes envolve compreender que os contextos de produção e circulação dos documentos educacionais oficiais são diferentes para cada um dos países. Além disso, segundo Garcia e Merken (2010), esses contextos se constituem a partir de uma enorme complexidade que abrange: a) os fatores externos à escola, processos nacionais de planejamento educacional, formulações de políticas, a legislação pertinente, os interesses das agências de fomento e de outras instituições em nível nacional, estadual, municipal; b) no âmbito da própria escola e seu entorno, as comunidades escolares, seus gestores, pais, professores e alunos na lida cotidiana de suas respectivas salas de aula à medida que atribuem sentido às diretrizes oficiais a partir de seus recursos ${ }^{1}$ materiais e simbólicos, de suas práticas de interpretação.

Assim, importa enfatizar que não apenas as motivações para a produção dos documentos (o americano e o brasileiro) são diferentes, mas também os contextos de produção e o de circulação dos textos são distintos. Observamos também que o sistema educacional americano tende a ser menos centralizado ${ }^{2}$ que o brasileiro devido a uma maior autonomia dos estados da federação. Tudo isso dificulta a comparação entre a proposta nacional e a estrangeira. Apesar dessa dificuldade, é válida a nossa preocupação em ressaltar que os contextos intra e extraescolares não são estáticos, pois há uma constante possibilidade de reconfiguração, ou uma impossibilidade de pré-determinar as várias configurações contextuais. A nosso ver, as possibilidades de significação dos documentos oficiais, quer sejam os nacionais, quer sejam os estrangeiros estão entrelaçadas à dinâmica e à variedade das circunstâncias contextuais. 


\section{A ORIGEM DA LEITURA DO PCN+ E DO NGSS}

O texto nacional escolhido foi o $\mathrm{PCN}^{3}+$ Ensino Médio (Física 2002), que é parte das Orientações Educacionais Complementares aos Parâmetros Curriculares Nacionais/ Ciências da Natureza, Matemática e suas Tecnologias. Quanto ao texto dos Estados Unidos, escolhemos os parâmetros de avaliação- NGSS (New Generation Science Standards, 2013). A proposta de comparar esses textos surgia a partir da ementa da Unidade Curricular- Inglês Instrumental I, ministrada no curso de Licenciatura em Ciências da Natureza com Habilitação em Física no IFSC-Campus de Jaraguá do Sul. Essa proposta tomou o formato de um projeto de extensão ${ }^{4}$ que tinha como prioridade fortalecer práticas interdisciplinares entre as áreas de linguagens e de educação científica e, assim, contribuir para a educação dos discentes da Licenciatura, professores em desenvolvimento. Durante um período de dois meses (agosto e setembro, 2015), analisamos os documentos, revisamos a literatura pertinente ao tema e apresentaremos abaixo as principais reflexões.

Escolhemos enfocar o PCN+ Ensino Médio (Física, 2002), pois no momento em que executamos o projeto, esse documento era analisado e citado pelos discentes em outras unidades curriculares do curso de Licenciatura. Embora a Base Nacional Comum Curricular (BNCC, 2015-6) já estivesse em tramitação, ainda não era vigente.

\section{DISCUSSÃO: É POSSÍVEL PRODUZIR UM CONSENSO ACERCA DE UMA BASE NACIONAL COMUM SEM CONSIDERAR UMA DISPUTA POR PROJEÇÕES CONTEXTUAIS LOCAIS?}

Em 1998, foram publicados os Parâmetros Curriculares Nacionais (PCN) e os Parâmetros Curriculares Nacionais- Ensino Médio (PCNEM). Conforme explica Lopes (2015), os documentos da década de 90 encontraram resistência entre os estudiosos de currículo apesar de sua divulgação ampla durante o mandato de Fernando Henrique Cardoso (1995- 2003) e apesar de tomarem como base legal a Lei de Diretrizes e Bases da Educação Nacional (Lei 9394/96) e a própria Constituição Federal/ 88 (Art.205 e Art.206). Ainda segundo Lopes (2015), as críticas partiam do entendimento que os parâmetros estariam vinculados à politica neoliberal da era FHC e, já naquela época, problematizava-se a tentativa de centralizar uma diretriz curricular comum em âmbito nacional. Durante a era FHC, em 2002, também foram lançados os PCN+ (Orientações Educacionais Complementares aos Parâmetros Curriculares Nacionais). Após a entrada do Partido dos Trabalhadores (a partir de 2003), surgiram novos documentos: OCEM (Orientações 
Curriculares Nacionais, 2006); Resolução CNE/ CEB 4/2010 (Diretrizes Curriculares Nacionais Gerais para a Educação Básica); Parecer CNE/CEB 05/2011 (Diretrizes Curriculares Nacionais para o Ensino Médio); Resolução CNE/CEB 2/2012 (Diretrizes Curriculares Nacionais para o Ensino Médio); Base Nacional Comum Curricular (BNCC, 2015-6). Os documentos nacionais da era PT foram acolhidos por críticas mais brandas, quando comparados aos parâmetros curriculares (LOPES, 2015).

\section{Quadro 1: Ordem cronológica das diretrizes oficiais a partir de 1995}

\begin{tabular}{|l|l|l|}
\hline \multicolumn{1}{|c|}{ GOVERNO } & \multicolumn{1}{c|}{ ANO } & \multicolumn{1}{c|}{ DOCUMENTOS } \\
\hline PSDB & 1998 & PCN e PCNEM \\
\hline PSDB & 2002 & PCN + \\
\hline PT & 2006 & OCEM/MEC \\
\hline PT & 2010 & CNE/ CEB 4/2010 (Edu. Básica) \\
\hline PT & 2011 & CNE/CEB 05/2011(Ensino Médio) \\
\hline PT & 2012 & CNE/CEB 2/2012 (Ensino Médio) \\
\hline PT & $2015-6$ & BNCC \\
\hline
\end{tabular}

Fonte: MEC

Por um lado, observamos pontos comuns aos documentos de âmbito nacional tanto aqueles da era FHC (1995- 2003), quanto os da era PT (a partir de 2003). Isto é, todos eles (tabela 1, logo acima) tentaram comtemplar a previsão da LDB 9394/96 $6^{5}$ de uma base nacional comum a ser complementada por uma parte diversificada que atenda as especificidades dos contextos socioculturais e econômicos das comunidades. A base comum visará promover as finalidades do ensino (Quadro 2, logo abaixo), ainda de acordo com a $\mathrm{LDB}^{6}$ :

\section{Quadro 2: Fundamentos legais das finalidades do ensino}

\begin{tabular}{|c|c|}
\hline FUNDAMENTO LEGAL & FINALIDADES DO ENSINO \\
\hline $\begin{array}{l}\text { LDB Art. } 2 \\
\text { CRFB Art.205 }\end{array}$ & $\begin{array}{l}\text { - aprimoramento humano } \\
\text { - preparo para o exercício da cidadania } \\
\text { - qualificação para o trabalho }\end{array}$ \\
\hline $\begin{array}{l}\text { LDB Art. } 35 \\
\text { (finalidades do ensino médio) }\end{array}$ & $\begin{array}{l}\text { - desenvolvimento de pensamento crítico } \\
\text { - formação ética e cidadã } \\
\text { - fortalecimento da autonomia do educando } \\
\text { - desenvolvimento de competências para continuar o aprendizado }\end{array}$ \\
\hline $\begin{array}{l}\text { CRFB } \\
\text { (são possíveis desdobramentos do Art.206) }\end{array}$ & $\begin{array}{l}\text { - criação de condições equânimes para o acesso, a permanência na } \\
\text { escola e para os egressos do ensino básico participarem de exames } \\
\text { nacionais } \\
\text { - melhoria da qualidade da educação }\end{array}$ \\
\hline
\end{tabular}

Fonte: LDB 9394/96 Art.2 e Art.35; CRFB/ 88 Art.205 e Art.206 
Por outro lado, reconhecemos que, no cotidiano da vida da escolar, existem diversas possibilidades de cumprimento ou de descumprimento das propostas articuladas pelos documentos oficias ainda que elas se encontrem consubstanciadas pela LDB e pela própria Constituição Federal. As possibilidades de concretização das propostas podem esbarrar nas práticas interpretativas das comunidades escolares, na subjetividade de seus participantes (professores, alunos, gestores, pais), nas (im)possibilidades de comunicação que emergem no cotidiano escolar entre professores, alunos, gestores, pais etc., também na distribuição desigual de recursos simbólicos e materiais. Diversos autores alinham-se a esse entendimento (GARCIA; MERKEN, 2010; GIMENEZ, 2009, entre outros). Por exemplo, Gimenez pondera que os documentos oficiais não respondem às condições de ensino/ aprendizagem que configuram a vida escolar (número de alunos por turma, escassez de recursos materiais e de tempo, entre outros).

Além disso, há também autores que problematizam o estabelecimento de princípios norteadores e genéricos a partir dos documentos oficiais. Por exemplo, Lopes (2015) argumenta que as múltiplas possibilidades de configuração contextual não podem ser definidas a priori. Segundo Lopes, as agendas contextuais não são estáticas e a partir do seu próprio movimento se constituem e se modificam. Nesse sentido, Lopes prevê que seria impossível produzir um consenso acerca de uma base nacional comum sem considerar uma disputa por projeções contextuais locais. Nas próprias palavras de Lopes (2015, p.448, nosso grifo): “Os contextos [...] não são objetos preexistentes à espera da ampliação da nossa capacidade de indicarmos suas fronteiras e assim identificá-las".

A partir de um viés mais crítico, a construção de uma base nacional envolveria alguma tentativa de padronização que pode invisibilizar as diversas possibilidades de (re)configuração dos contextos educacionais e negligenciar detalhes sutis, muitas vezes, dados qualitativos e difíceis de mensurar, mas essenciais à compreensão da dinâmica e da heterogeneidade dos contextos locais. Já uma posição mais conservadora reconhece que as diretrizes nacionais poderiam ter um efeito de mudar o ensino, ainda que potencial. Isto é, apesar do seu efeito potencial e norteador, os documentos oficiais não seriam inócuos. Essa parece ser a posição da Diretoria de Estudos Educacionais do INEP (2010) e do próprio MEC, uma vez que esse último órgão tem insistido na publicação de parâmetros, orientações, resoluções e diretrizes (tabela 1, acima) e instituiu projetos como o PNLD (Programa Nacional do Livro Didático), que necessariamente está vinculado às orientações das diretrizes oficiais. Ainda, a criação do SISU (Sistema de Seleção Unificada) para o ingresso em instituições públicas de ensino superior em âmbito nacional, patrocinado pelo MEC e vinculado ao Enem, envolveu um investimento oficial em diretrizes a partir das quais se busca propiciar aos egressos do ensino básico acesso a saberes e competências comuns e, assim, condições mais equânimes para a participação em exames nacionais. 
Em resumo, a expectativa oficial é que com o transcorrer do tempo, os textos norteadores possam vir a ter um impacto social e ético, não só porque podem influenciar a produção de materiais didáticos; mas também tornar-se uma matriz de referência para a construção das avaliações oficiais; criar condições mais equânimes para os egressos do ensino básico participarem de exames nacionais; informar a educação dos docentes e gestores; embasar a redação de editais federais. Além disso, à medida que tornam explicito "quanto ao que não conduz na direção desejada" (PCN+, Física, 2002, p.2), os documentos poderão despertar uma maior criticidade para os problemas das escolas e para as condições dos educadores e das comunidades.

Enquanto uma concepção legalista prevê uma Base Nacional Comum que deveria funcionar como uma ferramenta a favor da igualdade a partir da qual todo estudante brasileiro teria oportunidade de acesso a um conhecimento nacional comum, os autores que adotam uma visão crítica problematizam:

Preocupa-me, [...], discursos do campo educacional apostarem tão facilmente na ideia de uma base curricular comum, apoiados na proposta de distribuir conhecimentos iguais para todos, como se conhecimento fosse um objeto, um dado, uma coisa, a ser captado, registrado e depois distribuído. Preocupa-me como se desconsidera a dimensão do currículo como negociação que produz discursivamente conhecimento na escola em conexão com tantas outras produções socialmente instituídas (LOPES, 2015, p.456).

\section{RESULTADOS: POR ONDEM ANDAM OS TEXTOS...}

Na superfície do texto, observamos que o PCN+ (Física, 2002) tentava fornecer algum tipo de fundamento a partir da qual as decisões acerca do ensino ciências naturais seriam localmente tomadas. Conforme grifamos nas citações abaixo, o PCN+, explicitamente, sinaliza um cunho de diretriz geral à medida que declara à própria comunidade escolar a possibilidade de direcionar os trabalhos educacionais.

\footnotetext{
[...] a realidade educacional e os projetos pedagógicos da escola que expressam objetivos formativos mais amplos a serem alcançados, e que devem direcionar o trabalho de construção do conhecimento físico a ser empreendido (p.2, nosso grifo).

[...] fazer opções por determinada forma de ação ou encaminhamento das atividades não é tarefa simples, já que exige o reconhecimento do contexto escolar específico, suas caraterísticas e prioridades, expressas nos projetos dos professores e alunos e nos projetos pedagógicos da escolas (p.36, nosso grifo).
}

A partir desses fragmentos pode-se observar que textualmente o $\mathrm{PCN}+($ Física), já em 2002, reconhecia a importância da experiência localmente situada e da construção coletiva para a constituição das relações educacionais em suas diferentes dimensões: tanto no âmbito do plano político pedagógico da escola, quanto na lida cotidiana da sala de aula entre os professores e os 
alunos. A posição dos PCN+ é consoante com outros autores, por exemplo, Luke et al. (2013) reforçam a importância de uma preparação profissional que responda às contingências locais, que preste atenção às heterogeneidades e promova a agência de professores e alunos.

Um terceiro fragmento (abaixo) atribui ao professor autonomia para estabelecer seus objetivos de uma maneira sensível ao seu contexto, às especificidades da comunidade escolar e ao projeto pedagógico da escola sem explicitamente prescrever ou definir atitudes que devem guiá-los:

Caberá sempre ao professor, dentro das condições específicas nas quais desenvolve seu trabalho, em função do perfil de sua escola e do projeto pedagógico em andamento, selecionar, priorizar, redefinir e organizar os objetivos em torno dos quais faz mais sentido trabalhar. É muito provável que uma escola da periferia de uma cidade grande tenha estabelecido prioridades formativas diferentes daquelas de uma escola central de uma cidade de pequeno porte (p.5-6, nosso grifo).

Mesmo que os fragmentos apresentados acima façam declarações explícitas a favor do fortalecimento da agência do professor, da autonomia escola e de sensibilização para as configurações contextuais locais, a nosso ver, não é suficiente um documento educacional tomar uma posição clara, mesmo que se encontre consubstanciado pela LDB e em consenso com as pesquisas na área. Conforme ressalta Lopes, nenhum documento oficial está imune às configurações contextuais (LOPES, 2015) e às práticas interpretativas das comunidades escolares que podem (re)significar esses textos (GARCIA; MERKEN, 2010; LUCENA, 2015).

À medida que iniciamos a comparação entre os PCN+ (Física, 2002) e o NGSS (2013), fomos percebendo que esses documentos eram essencialmente diferentes (OLIVEIRA, 2015): (a) observa-se que a nova proposta de parâmetros de avaliação americana não precisa ser adotada pelos estados, já a diretriz curricular brasileira pretende ter abrangência nacional. Nos Estados Unidos, devido a uma maior autonomia dos estados da federação, o sistema educacional tende a ser menos centralizado que o brasileiro; (b) outra diferença é que tanto o PCN quanto o PCN+ são diretrizes curriculares, já a americana é claramente uma proposta de parâmetros de avaliação de desempenho- "(...) the emphasis placed on a particular Science and Engineering Practice or Crosscutting Concept in a performance expectation is not intended to limit instruction, but to make clear the intent of the assessments" (NGSS, APPENDIX A ${ }^{7}, 2013$, p.1, nosso grifo); (c) o texto norte-americano é muito mais recente.

Importa aqui mencionar que não apenas as motivações para a produção dos documentos (o americano e o brasileiro) são diferentes, mas também os contextos de produção e o de circulação dos textos são distintos, o que inibiu a comparação entre os documentos. As diferenças entre os dois países encontram-se não apenas em relação ao contexto econômico, político e 
histórico, mas, além disso, em outros níveis, existem diferenças que dizem respeito às escolas, às comunidades escolares, e aos sistemas educacionais, etc. Parece-nos, então, mais prudente evitar generalizações acerca das possibilidades de concretização da proposta americana.

Apesar de estarmos cientes da dificuldade de comparar o documento nacional e o estrangeiro, é possível enxergar alguns pontos comuns, a saber: ambos os documentos revelam a preocupação de não se ensinar ciências como uma coletânea de fatos isolados, mas sim de construir um conhecimento coerente a partir de temas transversais (crosscutting concepts) que transitam por disciplinas variadas. Os dois documentos estão preocupados com a contextualização da ciência e do ensino de ciências no contexto histórico e social. Ambos os documentos entendem que as competências para coexistir com o mundo físico não podem ser trabalhadas isoladamente, e sim integradas ao mundo tecnológico e social.

as competências para lidar com o mundo físico não tem qualquer significado quando trabalhadas de forma isolada. Competências em física para a vida se constroem em um presente contextualizado, em articulação com competências de outras áreas, impregnadas de outros conhecimentos (PCN+, 2002, p.2).

Por ser bem mais recente, o documento americano é explícito quanto à preocupação de ser sensível à conjuntura da atual revolução tecnológica. Esse texto é bem marcado quanto ao seguinte aspecto: as práticas de investigação científica e do design de engenharia devem caminhar de forma integrada à compreensão do conhecimento científico:

Given the importance of science and engineering in the 21 st century, students require a sense of contextual understanding with regard to scientific knowledge, how it is acquired and applied, and how science is connected through a series of concepts that help further our understanding of the world around us (NGSS, APPENDIX ${ }^{8}$ A, 2013, p.1).

No PCN+ (2002) foram privilegiados seis Temas Estruturadores com abrangência para organizar o ensino, a saber (p.19), (F1) Movimentos: variações e conservações; (F2) Calor, Ambiente, Fontes e Usos de Energia; (F3) Equipamentos Eletromagnéticos e Telecomunicações; (F4) Som, Imagem e Informação; (F5) Matéria e Radiação; (F6) Universo, Terra e Vida. Esses Temas Estruturadores podem ser confrontados às quatro Ideias Nucleares (Disciplinary Core Ideas), que estão mencionadas no NGSS (2013), a saber, PS1: Matter and Its Interactions (a Matéria e Suas Interações), PS2: Motion and Stability: Forces and Interactions (Movimento e Estabilidade: Forças e Interações), PS3: Energy (Energia), PS4: Waves and their Applications in Technologies for Information Transfer (Ondas e suas Aplicações nas Tecnologias de Transferência de Informação). 
Em resumo, muito embora existam diferenças bem amplas entre os contextos (americano e brasileiro), o que bloqueia uma comparação mais detalhada entre os PCN+ (2002) e o NGSS (2013), ainda conseguimos perceber alguns pontos compartilhados entre esses dois textos:

\section{Quadro 3: PCN+ (2002) e o NGSS (2013) recomendações comuns}

\begin{tabular}{|l|}
\hline \multicolumn{1}{c|}{ RECOMENDAÇÕES OFICIAIS } \\
\hline - superação da organização por disciplinas isoladas \\
- transversalidade (em inglês, a ideia de transversalidade se traduziu a partir de crosscutting concepts) \\
- articulação dos conhecimentos em processos interdisciplinares \\
- contextualização histórica e social da ciência \\
- ensino por investigação (inquiry based learning) \\
- preocupação com a realidade da escola \\
- fortalecimento da autonomia do professor \\
- PCN+- Temas Estruturadores/ NGSS- Disciplinary Core Ideas
\end{tabular}

Fonte: PCN+ (2002) e o NGSS (2013)

Observamos (tabela 3) recomendações em comum que dizem respeito a um alinhamento dos dois textos aos princípios defendidos pelas pesquisas na área de educação científica. No entanto, a concretização dessas recomendações nunca estará automaticamente assegurada. A própria noção do que é ensino por investigação ${ }^{9}{ }^{10}$ presente nos dois textos parece estar sujeita a diversas possibilidades de interpretação e implementação (ABD-EL-KHALICK et al., 2003). Assim, é nosso entendimento, juntamente com outros autores, que as propostas oficiais, até aquelas que são construídas de forma colaborativa, estão em conformidade com as leis nacionais e as pesquisas recentes, estão sujeitas às múltiplas configurações contextuais e às práticas interpretativas das comunidades escolares, quer sejam as recomendações nacionais, quer sejam as estrangeiras.

\section{CONSIDERAÇÕES FINAIS: A MULTIPLICIDADE DE AGENDAS}

Libâneo et al. (2012, p.166) explicam que tanto os fatores contextuais externos (socioeconômicos, históricos, políticos, legais, etc.) quanto os intraescolares (nível de organização escolar, nível de informatização da escola, carga horária e formação dos professores, qualidade dos recursos didáticos, número de alunos por turma, etc.) podem ter um impacto na qualidade da educação e na criação de oportunidades educacionais. Ressaltamos que não existem apenas os 
recursos materiais, mas existem também outras sutilezas, detalhes qualitativos e, assim, mais difíceis de mensurar, que podem contribuir para exacerbar as inequidades nos contextos educacionais, por exemplo, nível de autoestima das comunidades escolares, qualidade da interação entre a escola e a comunidade, etc. Importa aqui ressaltar que os contextos intra e extraescolares não são estáticos ou pré-determinados e os participantes da vida escolar têm alguma possibilidade de agência. Ainda que existam níveis diferentes de agência, há uma constante possibilidade de reconfiguração. Assim, qualquer comparação entre os documentos envolve: (1) discutir o papel das diretrizes curriculares oficiais em relação à possibilidade de transformar a educação; (2) visualizar os contextos de produção e implementação dos documentos oficiais a partir da enorme complexidade que surge de diferentes dimensões (nas direções top down, bottom up, side-by-side- usamos os termos conforme GARCIA; MERKEN, 2010, p.255). Ainda conforme essas autoras, essas dimensões se impactam mutuamente de forma dinâmica, mas não linear. No topo, encontram-se os fatores externos à escola, processos nacionais de planejamento educacional, formulações de políticas, a legislação pertinente, os interesses das agências de fomento e de outras instituições em nível nacional, estadual, municipal. No âmbito local, as comunidades escolares, seus gestores, pais, professores e alunos, todos com suas próprias subjetividades, no cotidiano da lida escolar, produzem/ atribuem sentido às diretrizes oficiais a partir de seus recursos materiais, simbólicos e das práticas interpretativas das comunidades escolares. Dessa forma, as propostas expressas nos documentos oficiais podem tanto ser implementadas, quanto contrariadas, resignificadas (GARCIA; MERKEN, 2010; LUCENA, 2015) e até ignoradas. Assim, reiteramos nossa reflexão: não é suficiente o documento educacional tomar uma posição clara, estar em conformidade com as leis e informado pelas pesquisas mais recentes, como também não basta $o$ texto ter sido construído de forma coletiva, pois a criação de oportunidades educacionais envolve a interação de uma multiplicidade de agendas em constante estado de reconfiguração.

Neste momento, não temos uma análise etnográfica de como as propostas oficiais estão sendo respondidas em âmbito local no cotidiano da escola. No entanto, assumimos uma posição de que qualquer discussão acerca do que ensinar/aprender, como ensinar/aprender e porque motivo ensinar/aprender alguma coisa não faz sentido fora das projeções contextuais locais.

\section{NOTAS}

1 Como recursos materiais, Libâneo et al. (2012, p.166) mencionam: nível de organização e de informatização da escola, carga horária dos professores, qualidade dos recursos didáticos, número de alunos por turma, o próprio espaço físico da escola e das salas de aula, entre outros. Já os recursos simbólicos, parecem-nos de ordem mais qualitativa e, por vezes, difícil de mensurar e até de definir, entre esses, citamos o nível de autoestima das comunidades. 
2 GARCIA; MERKEN (2010) comentam a questão da descentralização do sistema educacional norte-americano.

3 Optamos pela leitura da versão do $\mathrm{PCN}+$ (2002) disponibilizada pela Sociedade Brasileira de Física (SBF) em: <http://www.sbfisica.org.br/arquivos/PCN_FIS.pdf $>$. Acesso em 15 set. de 2015

4 O projeto de extensão intitulado "Língua inglesa aplicada ao ensino de ciências: uma proposta de formação multidisciplinar" recebeu apoio do IFSC por intermédio do edital APROEX- $\mathrm{n}^{\circ}$ 02/2015/ PROEX- chamada 2.

5 Art.26. Os currículos da educação infantil, do ensino fundamental e do ensino médio devem ter base nacional comum, a ser complementada, em cada sistema de ensino e em cada estabelecimento escolar, por uma parte diversificada, exigida pelas características regionais e locais da sociedade, da cultura, da economia e dos educandos.

6 Art.2. A educação dever da família e do Estado, inspirada nos princípios de liberdade e nos ideais de solidariedade humana, tem por finalidade o pleno desenvolvimento do educando, seu preparo para o exercício da cidadania e sua qualificação para o trabalho, nosso grifo (ver também CRFB/88, Art. 205). Art. 35. O ensino médio, etapa final da educação básica, com duração mínima de três anos, terá como finalidades: I- a consolidação e o aprofundamento dos conhecimentos adquiridos no ensino fundamental, possibilitando o prosseguimento de estudos; II- a preparação básica para o trabalho e a cidadania do educando, para continuar aprendendo, de modo a ser capaz de se adaptar com flexibilidade a novas condições de ocupação ou aperfeiçoamento posteriores; III- o aprimoramento do educando como pessoa humana, incluindo a formação ética e o desenvolvimento da autonomia intelectual e do pensamento crítico; IV- a compreensão dos fundamentos científico-tecnológicos dos processos produtivos, relacionando a teoria com prática, no ensino de cada disciplina.

7 “[...] a ênfase colocada em uma prática específica de ciência e engenharia ou em um tema transversal prevê uma expectativa de desempenho e não visa limitar a instrução, mas tornar clara a intenção das avaliações" (NGSS, APPENDIX A, 2013, p.1, nossa tradução).

8 Dada à importância da ciência e da engenharia no século 21, exige-se dos estudantes um senso de compreensão contextual acerca do conhecimento científico, como ele é adquirido e aplicado, e como a ciência está interligada por meio de uma série de conceitos que nos ajudam a compreender ainda mais o mundo ao nosso redor (NGSS, APPENDIX A, 2013, p.1, nossa tradução).

9 De forma breve o documento americano explica: “[...] scientific inquiry involves the formulation of a question that can be answered through investigation."- "[...] investigação científica envolve a formulação de uma pergunta que pode ser respondida por intermédio de uma investigação" (disponível em NGSS: <http://www.nextgenscience.org/three-dimensions> Acesso: 01 fev. 2016, nossa tradução).

${ }^{10} \mathrm{Na}$ opinião de LEDERMAN (2004), citado por (ABD-EL-KHALICK et al., 2004) nos Estados Unidos: apesar da flexibilidade e a independência serem atributos de reconhecida importância para os distritos escolares e para os estados americanos, valoriza-se também o desenvolvimento e implementação de temas comuns como o letramento científico e o ensino investigativo que serviriam como um esqueleto estruturante para o sucesso de todos "Although flexibility and independence are important for school districts and states, there is value in the development and implementation of coherent themes, such as scientific literacy and inquiry, that serve as guiding frameworks for all to achieve." (ABD-EL-KHALICK et al., 2004, p.402). 


\section{REFERÊNCIAS}

ABD-EL-KHALICK et al. Inquiry in Science Education: international perspectives. Science Education, v. 88, n. 3, p. 397-419, 2004.

BRASIL. MEC. Secretaria de Educação Média e Tecnológica. Parâmetros Curriculares Nacionais Ensino Médio (PCNEM): Ciências da Natureza, Matemática e suas Tecnologias. Brasília: MEC/SEMTEC, 1998. Disponível em <http://portal.mec.gov.br/seb/arquivos/pdf/ ciencian.pdf> Acesso: setembro 2015.

BRASIL. MEC. Secretaria da Educação Fundamental. Parâmetros Curriculares Nacionais (PCN): Ciências Naturais. Brasília: MEC/SEF, 1998. Disponível em < http://portal.mec.gov.br/s eb/arquivos/pdf/ciencias.pdf $>$. Acesso em: setembro 2015.

BRASIL. MEC. PCN+ Ensino Médio: orientações educacionais complementares aos Parâmetros Curriculares Nacionais. Ciências da Natureza, Matemática e suas Tecnologias (Física). Brasília: MEC, 2002 Disponível em: <http://www.sbfisica.org.br/arquivos/PCN_FIS. pdf > Acesso em: setembro 2015.

BRASIL, MEC. Secretaria de Educação Básica. Orientações Curriculares Nacionais para o Ensino Médio: Ciências da Natureza, Matemática e suas Tecnologias. Brasília: MEC/SEB, 2006. Disponível em: <http://portal.mec.gov.br/seb/arquivos/pdf/book_volume_02_internet.pdf> Acesso em: setembro 2015.

BRASIL. Resolução Conselho Nacional de Educação/Câmara da Educação Básica, no 4/2010. Define as Diretrizes Curriculares Nacionais Gerais para a Educação Básica. Brasília: aprovado em 13 jul. 2010. DOU, Brasília, 14 jul. 2010. Seção 1, p. 824. Disponível em: < http://portal.mec.gov.br/dmdocuments/rceb004_10.pdf >. Acesso em: janeiro 2016.

BRASIL. Resolução Conselho Nacional de Educação/Câmara da Educação Básica, no 2/2012. Define as Diretrizes Curriculares Nacionais para o Ensino Médio. Brasília: aprovado em 30 jan. 2012. DOU, Brasília, 31 jan. 2012. Seção 1, p. 20. Disponível em: < http://pactoensino medio.mec.gov.br/images/pdf/resolucao_ceb_002_30012012.pdf $>$. Acesso em: janeiro 2016.

BRASIL. Parecer Conselho Nacional de Educação/Câmara da Educação Básica, n 05/2011.: Diretrizes Curriculares Nacionais para o Ensino Médio. Brasília: aprovado em 04 maio 2011. DOU, Brasília 24 jan. 2012. Seção 1, p. 10. Disponível em: <http://pactoensinomedio. mec.gov.br/images/pdf/pceb005_11.pdf >. Acesso em: janeiro 2016.

BRASIL. MEC. Base Nacional Comum Curricular (BNCC). Brasília: MEC, 2015-6. Disponível em <http://basenacionalcomum.mec.gov.br/\#/site/inicio $>$. Acesso em: janeiro 2016.

BRASIL. MEC. Diretoria de Estudos Educacionais do INEP. Melhores Práticas em Escolas de Ensino Médio no Brasil. Brasília: INEP, 2010. Disponível em <http://pactoensinomedio. mec.gov.br/images/pdf/melhores_praticas_ensino_medio.pdf $>$ Acesso em: janeiro 2016.

BRASIL. Presidência da República/Casa Civil. Constituição da República Federativa do Brasil (CRFB, 1988). Disponível em: <http://www.planalto.gov.br/ccivil_03/Constituicao/Constituicao. $\mathrm{htm}>$. Acesso em: janeiro 2016.

BRASIL. Lei de Diretrizes e Bases da Educação Nacional (LDB). Lei nº 9.394, de 20 de 
dezembro de 1996. Estabelece as diretrizes e bases da educação nacional. Disponível em: <http:// presrepublica.jusbrasil.com.br/legislacao/109224/lei-de-diretrizes-e-bases-lei-9394-96>. Acesso em: janeiro 2016.

GARCIA, O.; MENKEN, K. Stirring the onion: Educators and the dynamics of language education policies (looking ahead). In: MENKEN, K.; GARCIA, O. (Orgs). Negotiating language education policies: educators as policy makers. New York: Routledge, 2010, p.249-261.

GIMENEZ, T.N. Diretrizes Curriculares e a sala de aula de língua estrangeira: diálogos (im)possíveis? In: CORREA, D.A.; SALEH, P.B.O. (Orgs.). Estudos da linguagem e currículo: diálogos (im)possíveis. Ponta Grossa: Editora UEPG, 2009.

LIBÂNEO, J.C; OLIVEIRA, J.F de; TOSCHI, M.S. Educação escolar: políticas, estrutura e organização. 10 ed. rev. ampl. São Paulo: Cortez, 2012.

LOPES, A. C. Por um currículo sem fundamentos. Linhas Críticas, Brasília, DF, v.21, n.45, p. 445-466, mai./ago. 2015.

LUCENA, M.I.P. O papel da pesquisa de cunho etnográfico na discussão das políticas educacionais de línguas. In: FRITZEN, M. P.; LUCENA, M.I.P. (Orgs.). O olhar da etnografia em contextos educacionais: interpretando práticas de linguagem. Blumenau: Edifurb, 2012, p.119-135.

LUKE, A.; WOODS, A.; WEIR, K. Curriculum design, equity and the technical form of the curriculum. In: LUKE, A.; WOODS, A.; WEIR, K. (Orgs.). Curriculum, syllabus design and equity: a primer and model. New York: Routledge. 2013, p.6-39.

OLIVEIRA, E.C de. Documentos oficias em língua materna e estrangeira e o seu efeito potencial. Comunicação pessoal proferida na Semana Nacional de Ciência e Tecnologia/ IFSC, Jaraguá do Sul, 2015.

The National Research Council (NRC); The National Science Teachers Association (NSTA), The American Association for the Advancement of Science and Achieve. Next Generation Science Standards (NGSS, 2013). APPENDIX A - Conceptual Shifts in the Next Generation Science Standards. Disponível em <http://www.nextgenscience.org/sites/ngss/files/Appendix\% 20A\%20$\% 204.11 .13 \% 20$ Conceptual $\% 20$ Shifts $\% 20$ in $\% 20$ the $\% 20 \mathrm{Next} \% 20$ Generation $\% 20$ Science $\% 20$ St andards.pdf $>$. Acesso em: outubro 2015. 